\title{
Angiocardiographic appearances of atrioventricular defects with particular reference to distinction of ostium primum atrial septal defect from common atrioventricular orifice
}

\author{
FERGUS J. MACARTNEY, PHILIP G. REES, KIERAN DALY ${ }^{1}$, \\ GIAN PIERO PICCOLI ${ }^{2}$, JAMES F. N. TAYLOR, MARC R. DE LEVAL, \\ JAROSLAV STARK, AND ROBERT H. ANDERSON ${ }^{3}$
}

From the Thoracic Unit, The Hospital for Sick Children, Great Ormond Street, London

SUMMARY Preoperative distinction between common atrioventricular orifice and ostium primum atrial septal defect may be difficult.

To improve diagnostic accuracy, the right and left ventricular angiocardiograms were reviewed 'blind' in 92 patients with atrioventricular defects. The true diagnosis was known from necropsy or surgery in 60 . Angiocardiograms had been obtained in various projections with or without craniocaudal tilt. Those features thought to distinguish between common orifice and ostium primum were coded, together with the ventricular systolic pressures.

Computerised discriminant function analysis identified the following distinguishing features: (1) right ventricular systolic pressure; (2) immediate right ventricular outflow tract opacification from the left ventricle; (3) identification of the anterior attachment of the mitral component; (4) recognition of a single straddling atrioventricular orifice; (5) passage of contrast medium above or below the anterior or posterior bridging leaflets.

Feature (3) indicates that in contrast to classic teaching the direct septal attachment of the mitral component does not contribute to the 'gooseneck' in complete atrioventricular defects. The significance of (4) and (5) is that they may be identified from right as well as left ventriculography, and are more likely to be identified in oblique than standard projections. Computerisation produced a correct diagnosis in 92 per cent of known cases, and determined precise probabilities of diagnosis in the remainder.

The angiographic abnormalities which characterise atrioventricular defects were first described in a classic paper by Baron et al. (1964). These authors clearly described the manner in which the abnormal septal attachment of the mitral valve in this condition produces, in the frontal angiocardiogram, the appearance of the 'gooseneck' deformity of the left ventricular outflow tract. It was 10 years before

\footnotetext{
${ }^{1}$ Present address: St. Bartholomew's Hospital, London.
}

2Present address: Istituto per lo studio e la cura delle Malattie Reumatiche e Cardiovascolari Ospedale Specializzato Regionale 'G. M. Lancisi', 60100 Ancona, Via U. Baccarani 6, Italy. 3Present address: Cardiothoracic Institute, Fulham Road, London SW3.

FJM is supported by the Vandervell Foundation and RHA by the Joseph Levy Foundation, both together with the British Heart Foundation.

Received for publication 20 December 1978.
Blieden and his colleagues (1974) correctly pointed out that the deformity present was not simply one of the gooseneck (left ventricular outflow tract) but also of the goose (deficiency of the diaphragmatic wall of the left ventricle), but these authors continued to relate the angiocardiographic appearances to the left ventricular septum rather than to its free wall.

The logic of these arguments seems clear when applied to the partial defect (ostium primum atrial septal defect). However, it was difficult to understand how the same reasoning could be applied to the diastolic appearances of the complete defect (common atrioventricular orifice), since here there is rarely any direct attachment of the bridging anterior atrioventricular leaflet to the crest of the septum. Such a direct attachment is necessary to visualise atrioventricular leaflets angiocardiographically since it is essential to have a pronounced difference in 
opacification of blood on the two sides of the leaflet. Thus, we reasoned that in common atrioventricular orifice, the characteristic radiological appearance should result not from the abnormally positioned septal attachment of the mitral component, as in the ostium primum defect, but rather from its absence. Yet both conditions can present with similar abnormalities of attachment of the mitral component! Since the similarity could not be the result of the septal attachment, the two conditions must have in common an abnormal free wall attachment. But the latter had been almost ignored in the published reports, and when mentioned, had been specifically stated to be normal (Baron et al., 1964; Somerville and Jefferson, 1968). If this reasoning were correct, it would follow that analysis of the type of attachment present would help to distinguish partial from complete defects.

Furthermore, in the complete defect, the absence of direct septal attachments of the anterior leaflet applied to both mitral and tricuspid components. Accordingly, despite the fact that previous attempts to demonstrate abnormalities on right ventricular angiocardiography had failed, apart from showing non-specific tricuspid regurgitation (Baron et al., 1964; Rastelli et al., 1967), we reasoned that they must indeed exist.

Finally, as many of the points of preoperative differentiation between ostium primum atrial septal defect and common atrioventricular orifice are suggestive, but not specific (Rastelli et al., 1967), it seemed that computer-assisted diagnosis using multivariate analysis might improve accuracy.

With these considerations in mind, we studied the angiocardiograms of the 92 patients with atrioventricular defects who had been investigated since 1967.

\section{Subjects and methods}

All patients reported had undergone cardiac catheterisation, and all but two had also had selective left ventriculography at The Hospital for Sick Children over the past 10 years. The diagnosis of either ostium primum atrial septal defect or common atrioventricular orifice had been established either by angiocardiography, at open-heart surgery ( 45 patients who survived), or at necropsy (15 patients). Thus in 60 patients $(65.2 \%)$ there was independent confirmation of the angiocardiographic diagnosis. Patients with rarer forms of partial defects, such as inlet ventricular septal defect with cleft mitral valve and intact atrial septum, were excluded, as were those with a univentricular heart. Common atrioventricular orifice was defined as that condition in which there was no continuity over the septal crest between the anterior and posterior leaflets, whereas in ostium primum atrial septal defect leaflet continuity at this point divided the atrioventricular canal into separate mitral and tricuspid valves (Wakai and Edwards, 1958; Bharati and Lev, 1973). The terminology employed by Piccoli et al. (1979a, b) will be used throughout to describe the anatomical features.

The angiocardiograms were all reviewed by one observer (FJM), without knowledge of the patient's name, diagnosis, or haemodynamic status. In a small proportion of cases, this analysis could not have been completely blind, because the angiocardiogram was recognised as belonging to a recently investigated patient, but as many of such patients had not yet undergone open-heart surgery, the analysis was truly blind in at least 90 per cent of cases.

Particular note was paid in all films to the appearance of the annulus of a common valve or the mitral and tricuspid valve annuli as seen during diastole. Diastole was easily identified on cine angiocardiograms, but had to be inferred from the state of the atrioventricular and semilunar valves on large film angiocardiograms taken at six per second.

In anteroposterior projections, the septal (anterior) attachment of the mitral valve was regarded as identified with certainty if a diastolic cleft was seen, that is a fine jet of non-opacified blood entering the left ventricular cavity during protodiastole, before full opening of the mitral valve. The site of this cleft invariably corresponded with the site of the systolic jet of mitral regurgitation, if present.

The free wall (posterior) attachment of the mitral valve or mitral component of the common atrioventricular valve was regarded as positively identified if the left circumflex coronary artery was seen in close relation to it throughout at least 80 per cent of its length. In left anterior oblique projections, with (Bargeron et al., 1977; Elliott et al., 1977; Rees et al., 1978) and without (Brandt et al., 1972; Brandt, 1973) craniocaudal tilt, the distinction of free wall from septal attachment is obvious as the projection is chosen in order to separate the left ventricular septum from its free wall. Nevertheless, the relation between the circumflex artery and the free wall attachment was noted. Craniocaudal tilt was obtained by raising the patient's shoulders so as to bring the thorax to $45^{\circ}$ from the table top, and then rotating the left shoulder forward through $30^{\circ}$. Craniocaudal tilt is strictly only applied to the projection obtained with the vertical tube and camera, but the simultaneously exposed view in the horizontal plane at right angles to the long axis of the table is loosely referred to as right anterior oblique with craniocaudal tilt. 
Where a single, complete, undivided ring of atrioventricular leaflet attachment was visualised overriding the trabecular (muscular) interventricular septum, the angiocardiogram was held to demonstrate a common atrioventricular orifice.

The atrioventricular annulus or annuli are not the only structures which produce a sharp diastolic interface between opacified and non-opacified blood. The leaflets themselves also produce this appearance. On cine angiocardiography leaflets are easily distinguished from annuli by their rapid movement and particularly by the ' $M$ ' shaped flutter so well known to echocardiographers. However, it is also apparent from cine angiocardiograms that leaflets tend to be straighter than annuli, and this provides a means of distinguishing the two on large film angiocardiograms taken at six per second. The relation between the anterior mitral (or common anterior) leaflet and the left ventricular line of attachment of the valve was noted particularly on frontal angiocardiograms.

In systole, attention was paid to the presence of filling of the right ventricular outflow tract on the first systole, and to demonstration of the passage of contrast medium from either ventricle to the other above or below a bridging left anterior, separate left and right anterior, or a bridging posterior leaflet of the common atrioventricular valve. In addition, evidence of a filling defect in the presumed region of the mitral valve was sought, and the presence or absence of a systolic gooseneck deformity of the left ventricular outflow tract was noted.

It became apparent that there was no possibility of identifying the varieties of papillary muscle attachment of the left anterior leaflet angiocardiographically in common atrioventricular orifice, but an attempt was made, in the light of the operative or necropsy diagnosis, to distinguish anterior or posterior leaflets attached by chordae tendineae to the crest of the ventricular septum from those which were 'free-floating' (Rastelli et al., 1966).

These observations were then coded, punched onto cards, and analysed at The University of London Computer Centre, using the Statistical Package for the Social Sciences for cross-tabulation and discriminant function analysis (Nie et al., 1975). Stepwise entry of variables into the discriminant equation was assessed by their ability to minimise Wilks' lambda. Classification was weighted according to the proportion of patients in each known diagnosis category. The discriminant functions were based upon the 60 patients with independent confirmation of the diagnosis, and then applied to the remaining 32 , so as to give a haemodynamic/ angiocardiographic diagnosis, together with a probability of its being correct. It is this probability that is quoted in the figure legends.

\section{Results}

Only selective right and left ventricular angiocardiograms were analysed. In all, 151 films were reviewed, $137(90.7 \%)$ of these having been taken in two planes at right angles to one another. Table 1 gives details of the injections and projections used.

Table 1 Ventricular angiocardiograms in 92 patients

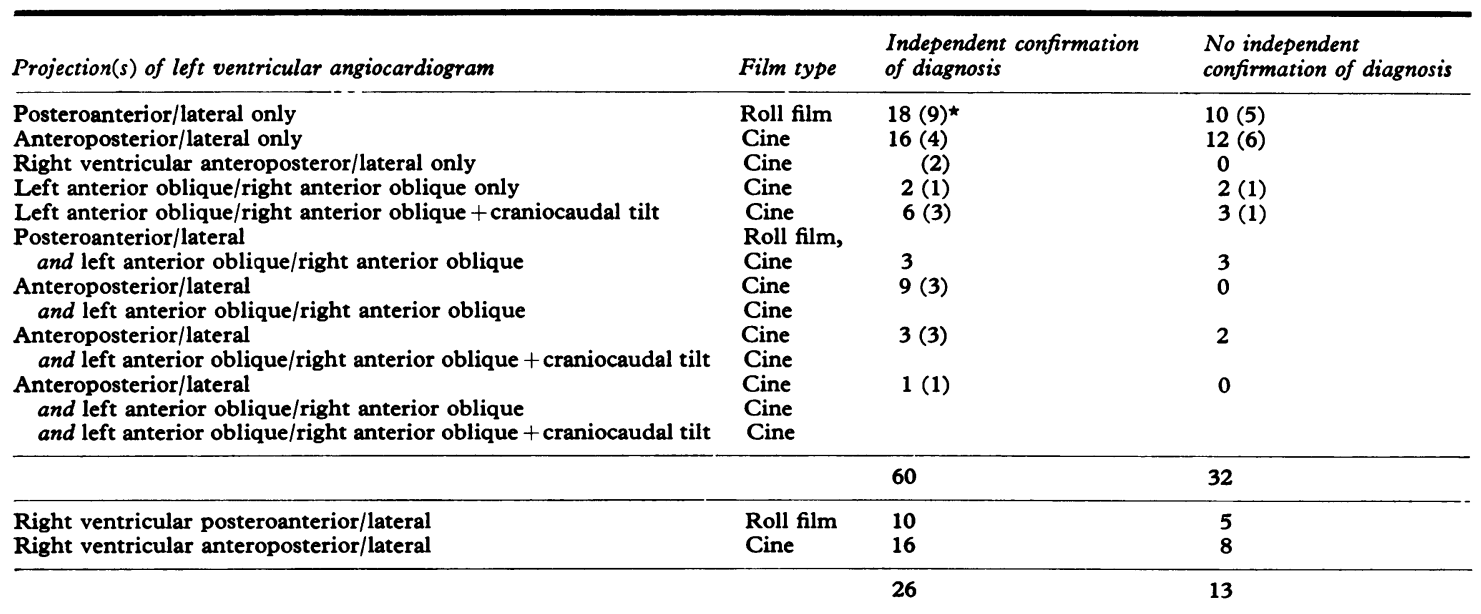

*Parentheses indicate number who also had an RV angio of any type (invariably biplane in frontal and lateral projections). In 14 of the 151 films $(9 \cdot 3 \%)$ the films were in only one projection, but the details have been omitted for simplicity. Two were lateral films only, six craniocaudal tilt, and six left anterior oblique only. 
In brief, $39(25.8 \%)$ were right ventricular angiocardiograms in the frontal and lateral planes. In 112 $\left(74.2^{\circ} \%\right)$, injection was into the left ventricle. Seventy-seven $(68.8 \%$ ) left ventricular angiocardiograms were in the frontal or lateral projections, and $35(31.2 \%)$ were in oblique projections, to which craniocaudal tilt had been added in 15 .
IDENTIFICATION OF ANTERIOR AND POSTERIOR ATTACHMENTS OF MITRAL VALVE (OR COMPONENT) (Table 2)

A diastolic cleft was identified in five frontal cine angiograms and 17 frontal roll films. The line of attachment associated with this diastolic cleft was invariably puckered (Fig. 1A cf. with Fig. 1C, 2A).
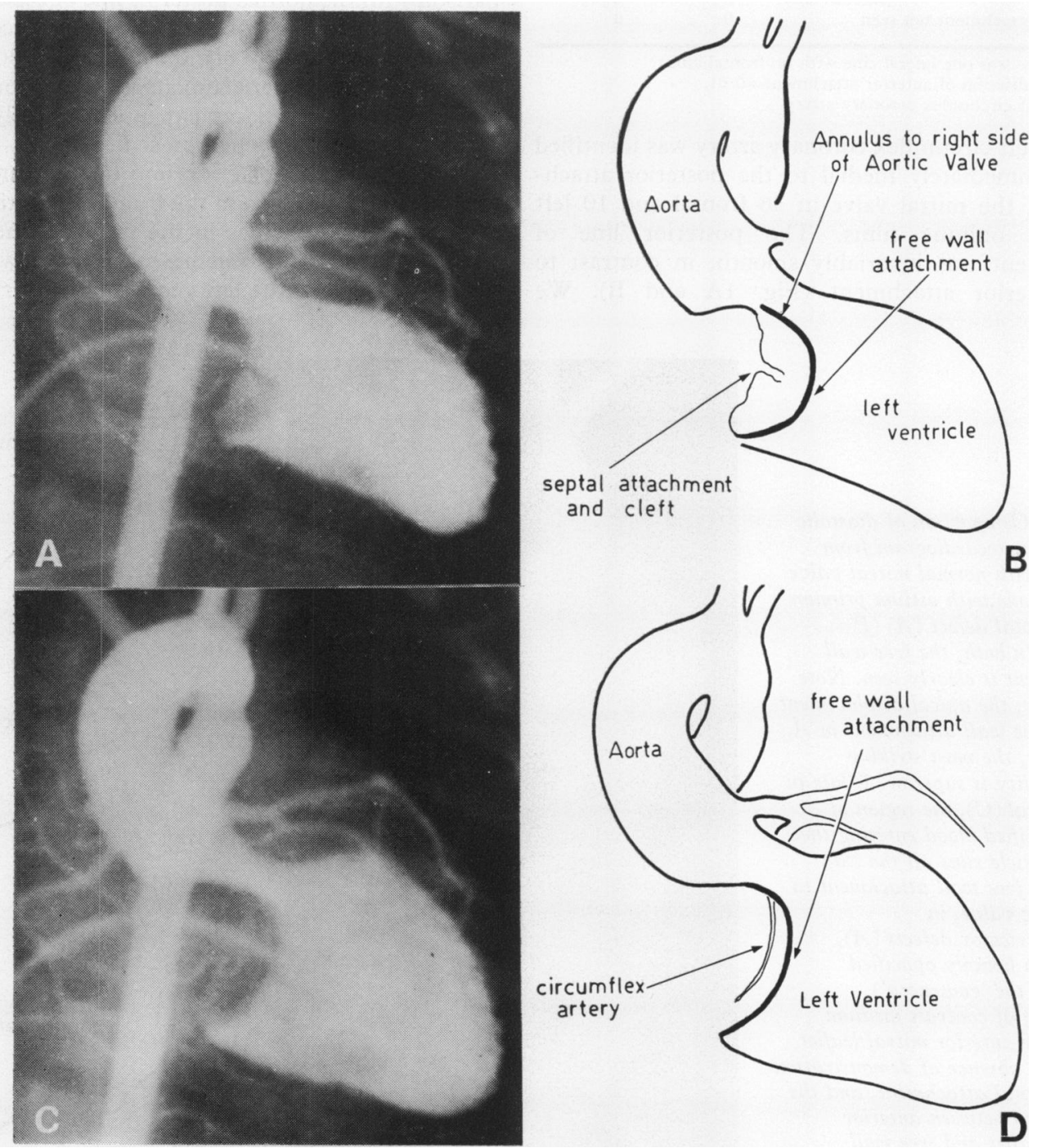

Fig. 1 Frontal left ventricular angiocardiogram. Two diastolic frames from a patient with ostium primum atrial septal defect $(P=0.997)$. Note that a 'gooseneck' deformity is present in $A$ and $C$. However in $C$ it is formed by the smooth free wall mitral valve attachment alone, whereas two 'goosenecks' are visible in $A$. That formed by the free wall attachment is still visible, but the most prominent is due to the classical appearance of the septal attachment, marked by puckering and a diastolic cleft. The circumflex coronary artery is faintly seen in $C$ immediately medial to the free wall attachment. 
Table 2 Left ventricular frontal cine angiocardiograms in patients with independent confirmation of diagnosis

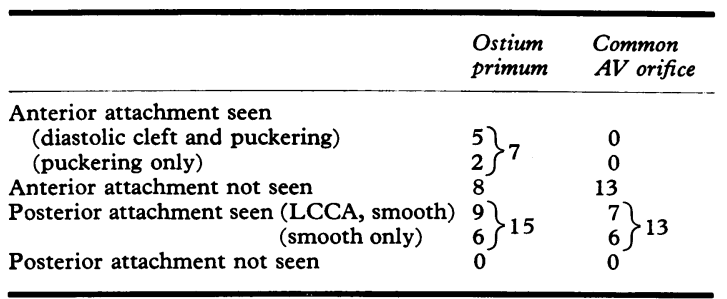

N.B. There was one lateral cine with no frontal cine.

$P$ for visualisation of anterior attachment $=0.01$.

LCCA, left circumflex coronary artery.

The left circumflex coronary artery was identified lying immediately medial to the posterior attachment of the mitral valve in 36 frontal and 10 left anterior oblique films. The posterior line of attachment was invariably smooth, in contrast to the anterior attachment (Fig. 1A and B). We concluded that a puckered attachment is anterior and a smooth attachment is posterior even if the diastolic cleft and left circumflex coronary artery are not seen.

In only four films $(2 \cdot 6 \%)$ was no posterior line of attachment seen. Whether identified in the frontal or left anterior oblique projection, with or without craniocaudal tilt, the inferior end of the posterior attachment was always displaced apically by comparison with the normal posterior line of attachment (Fig 2, 3,9). This apical displacement was occasionally subtle, but usually obvious. Since the posterior and anterior lines of attachment are continuous with one another, this displacement applied equally to the anterior attachment, when present.

Superiorly, the posterior line of attachment of the mitral valve as seen in the frontal projection was also abnormal. Whereas in the normal patient the posterior attachment becomes continuous with the lateral free wall of the left ventricle before running
Fig. 2 Comparison of diastolic frontal angiocardiogram from patient with normal mitral valve $(C)$ and one with ostium primum atrial septal defect $(A)(P=$ 0.998 ). In both, the free wall attachment is clearly seen. Note inferiorly, the apical displacement of the free wall attachment in $A$. However, the most striking abnormality is superior. While in the normal $(C)$, the region of non-opacified blood entering the left ventricle runs all the way from the free wall attachment to the aortic valve, in atrioventricular defects $(A)$, there is a heavily opacified 'tunnel' (the 'gooseneck') consisting of contrast medium above the anterior mitral leaflet. Note the absence of demonstration of the septal attachment, and the angulation between anterior mitral leaflet and free wall attachment.
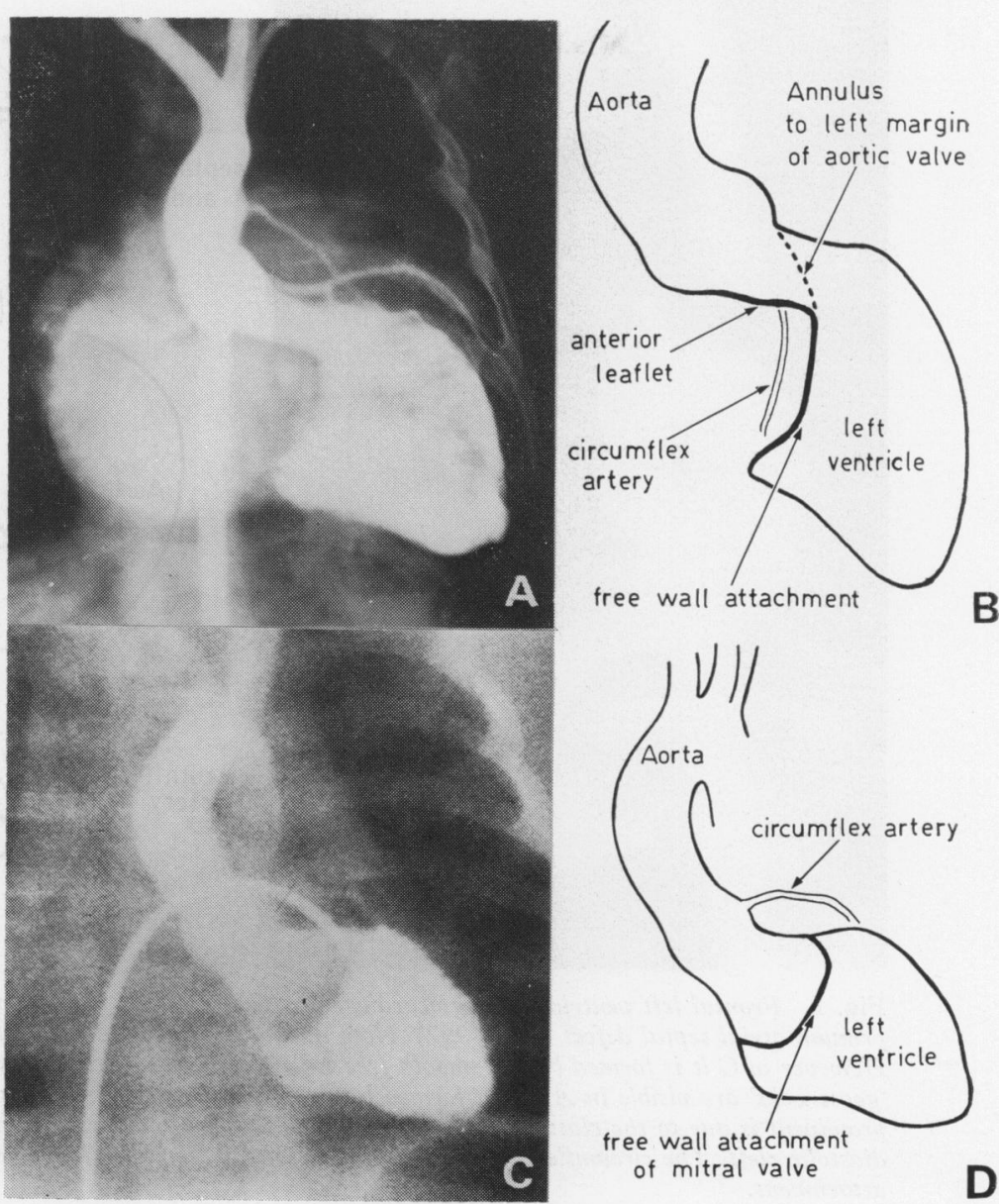
onto the left coronary cusp of the aortic valve (Fig. 2C, D), in these patients with atrioventricular defects, though the posterior line of attachment could sometimes be seen to merge normally with the leftward margin of the aortic valve (Fig. 2A, B), it occasionally ran up to the middle of the valve, and more frequently apparently to the right side of the valve (Fig. 1). The word 'apparently' is used because the anterior mitral (or common leaflet) also hinges on the rightward margin of the aortic valve, and it is difficult on roll films to distinguish between leaflet and annulus at this point. However, whatever the precise reason for this appearance, the fact remains that whereas in the normal frontal left ventricular angiocardiogram the ring of nonopacified blood entering during diastole runs up to the whole width of the aortic valve (Fig. 2C), in atrioventricular defects there is a wedge of contrast medium separating the left margin of the aortic valve from the non-opacified blood entering the left ventricle (Fig. 1, 2A). This forms the diastolic gooseneck deformity.

When present, that is in ostium primum defects, the anterior attachment normally lay more or less directly anterior to the posterior attachment, both in its upper region where it approached horizontal, and more caudally where it approached vertical (Fig. 1A).

In left anterior oblique projections, with or without craniocaudal tilt, even if the detail of the posterior attachment of the mitral valve (or component) was partially obscured by preceding mitral regurgitation, non-opacified blood (and indeed a cardiac catheter) was seen to enter the left ventricle from a highly

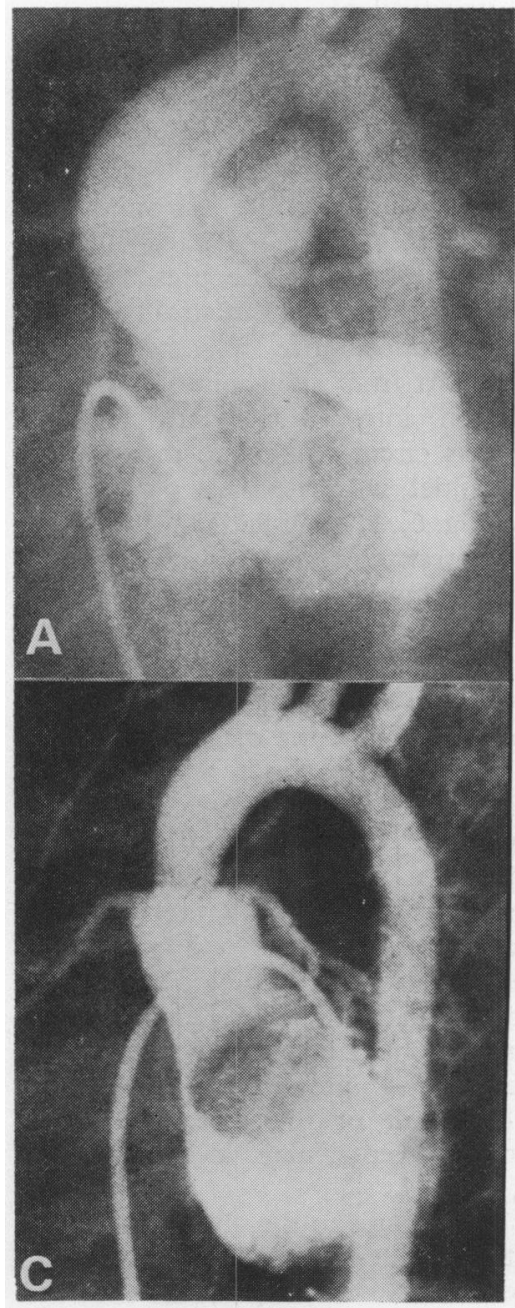

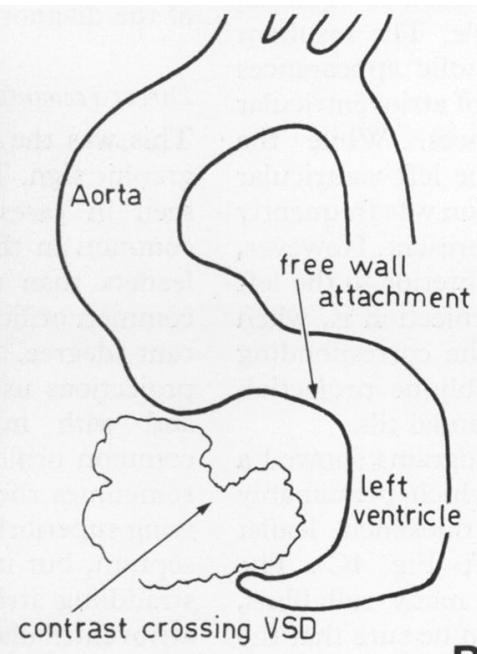

B

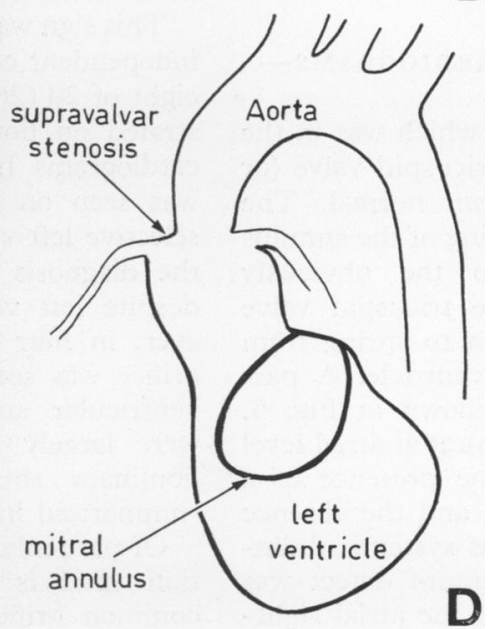

Fig. 3 Comparison of appearances of diastolic left anterior oblique left ventricular angiocardiograms in patient with normal mitral valve $(C)$ and common atrioventricular orifice (A) $(P=0.986)$. Note that in the atrioventricular defect $(A)$, the mitral annulus seems to spring from the septum anteriorly, whereas the normal mitral annulus (C) only makes tenuous contact with the ventricular septum. No septal attachment of the mitral valve is seen in $(A)$; instead contrast medium has in the previous systole crossed the entire common orifice to opacify the right ventricle, and hence the pulmonary atery. The patient in (C) had supravalvar aortic stenosis in association with the idiopathic hypercalcaemia syndrome. Note that the catheter appears to enter the left ventricle in this projection from behind when the mitral valve is normal, but from in front in atrioventricular defects. 
abnormal direction, that is from above and in front of as opposed to above and behind the left ventricle, as viewed in this projection (Fig. 3). In the lateral view, while the mitral annulus was seen to be abnormally anterior in a few patients, the diastolic appearances were in general not diagnostic.

\section{SYSTOLIC APPEARANCES-GENERAL}

\section{COMMENTS}

The majority of angiocardiograms were obtained with the catheter through the mitral valve (or component), which exacerbated the usual (but not invariable) mitral regurgitation. The left anterior oblique projection with craniocaudal tilt separates left from right atrium well, and it was clear that the jet of mitral regurgitation was directed largely or entirely into the right atrium in all patients.

Because of mitral regurgitation, opacification on either side of the mitral leaflets tended to equalise, more so in systole than in diastole. The resultant loss of definition meant that systolic appearances were in general far less diagnostic of atrioventricular defects than diastolic appearances. While the systolic gooseneck deformity of the left ventricular outflow tract in the frontal projection was frequently seen, it was just as frequently not present. However, ballooning of mitral valve tissue anterior to the left ventricular cavity in the lateral projection is, when seen, diagnostic (Fig. 4A) as is the corresponding appearance in the left anterior oblique projection (Fig. 4C) with or without craniocaudal tilt.

Careful study of cineangiocardiograms showed a systolic 'cleft' in nine patients, which presumably represented apposition of the thickened leaflet margins in the region of the cleft (Fig. 4C). The same appearance was present in many roll films, though here it was more difficult to be sure that the film was systolic.

\section{RIGHT VENTRICULAR ANGIOCARDIOGRAMS- GENERAL APPEARANCES}

In only 15 films $(38.5 \%)$, one of which was in the lateral projection only, was the tricuspid valve (or component) indistinguishable from normal. The most subtle abnormality was shifting of the annulus leftwards, which progressed to the obviously abnormal situation in which the tricuspid valve appeared in the frontal projection to spring from the lateral margin of the right ventricle. A particularly interesting example is shown in Fig. 5. This patient had a bidirectional shunt at atrial level and was clinically cyanotic in the presence of a normal right ventricular pressure and the absence of a common atrium or anomalous systemic drainage. At operation an ostium primum defect was closed uneventfully. The cause of the atrial right- to-left shunt was hypoplasia of the tricuspid valve and right ventricle. The frontal angiocardiograms (Fig. 5) in this patient in fact show distinct leftward displacement of both tricuspid and mitral free wall attachments resulting in an abnormally large mitral and an abnormally small tricuspid orifice. This anatomy corresponds, in an ostium primum defect, to the dominant left ventricle variety of the complete defect as described by Bharati and Lev (1973).

The abnormalities on right ventricular angiocardiography are pertinent to the next section and will be discussed there.

\section{DIFFERENTIATION OF OSTIUM PRIMUM ATRIAL SEPTAL DEFECT FROM COMMON ATRIOVENTRICULAR ORIFICE}

This section is based, unless stated otherwise, upon the 60 patients in whom independent confirmation of the diagnosis was available.

\section{Direct recognition of common atrioventricular orifice}

This was the single most informative angiocardiographic sign. Table 3 demonstrates that it was never seen in cases of ostium primum. It was more common in the presence of 'free-floating' anterior leaflets than attached ones in the presence of a common orifice, though not to a statistically significant degree. This appearance was seen in all projections used apart from right anterior oblique, and with injection into either ventricle. The common orifice was circular or ovoid in shape, or sometimes rhomboidal, with the short parallel side lying superiorly (Fig. 6). It straddled the ventricular septum, but in contrast to the majority of cases of straddling atrioventricular valves without common atrioventricular orifice (Liberthson et al., 1971), no second atrioventricular orifice was demonstrated.

This sign was seen in a further 10 patients without independent confirmation of the diagnosis. In only eight of $20(26.7 \%)$ was a common orifice demonstrated on both right and left ventricular angiocardiograms. Indeed in 26.7 per cent this appearance was seen on selective right ventricular, but not selective left ventricular angiocardiography; that is the diagnosis of common orifice was established despite left ventricular angiocardiography. However, in four of 30 patients $(13.3 \%$ ), a common orifice was seen on left ventricular, but not right ventricular angiocardiography. These differences were largely the result of the direction of the dominant shunt at ventricular level, and are summarised in Table 4.

Of particular importance to the choice of projection used is the incidence of identification of common orifice related to the projection of left 
ventricular angiocardiography used (Table 5). In 14 of $18(77.8 \%)$ frontal or lateral angiocardiograms, no common orifice was shown though it was known that it existed. By contrast, this failure to demonstrate a common orifice when present occurred in only two of $11(18.2 \%)$ left anterior oblique angiocardiograms with and without craniocaudal tilt.

These differences could not be explained by differences in the underlying diagnosis. It seems clear that oblique projections are more likely to show a common orifice if it in fact exists.

Systolic traverse of contrast medium across different components of the common orifice

It was often possible, with injection into either the right or left ventricle, particularly in oblique

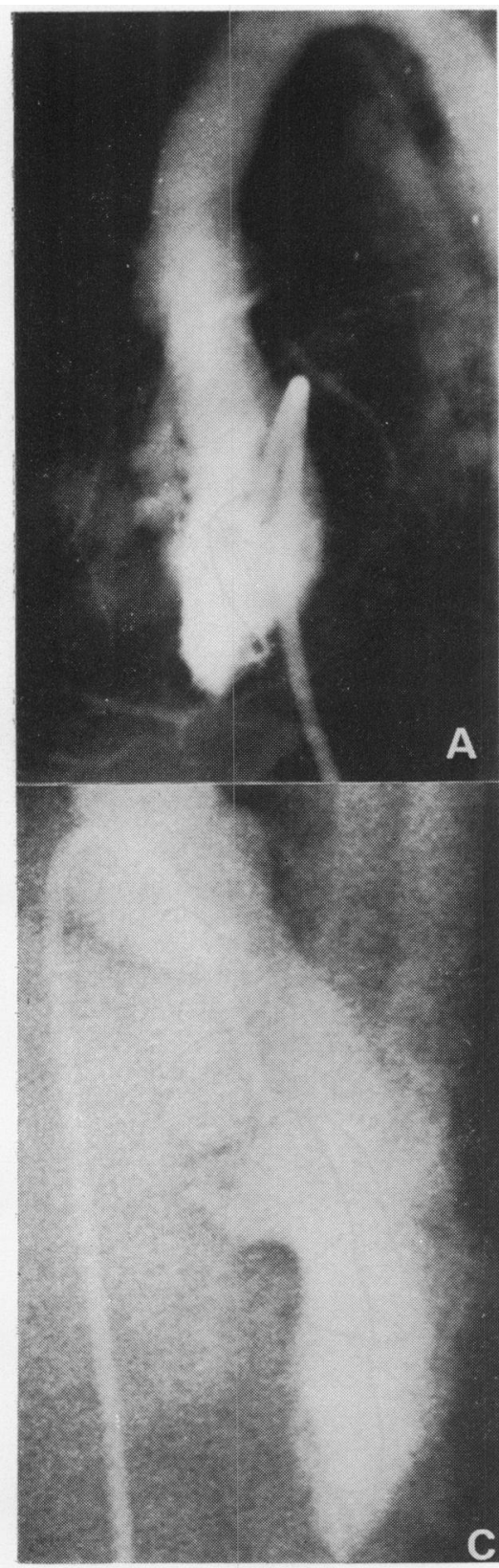

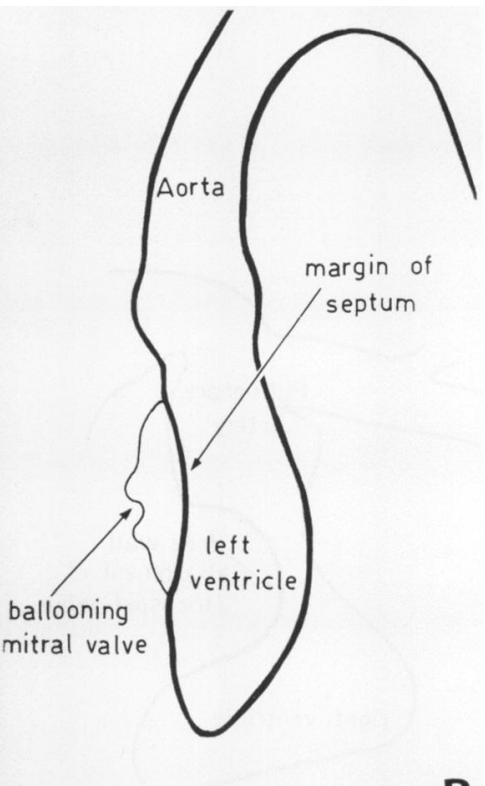

B

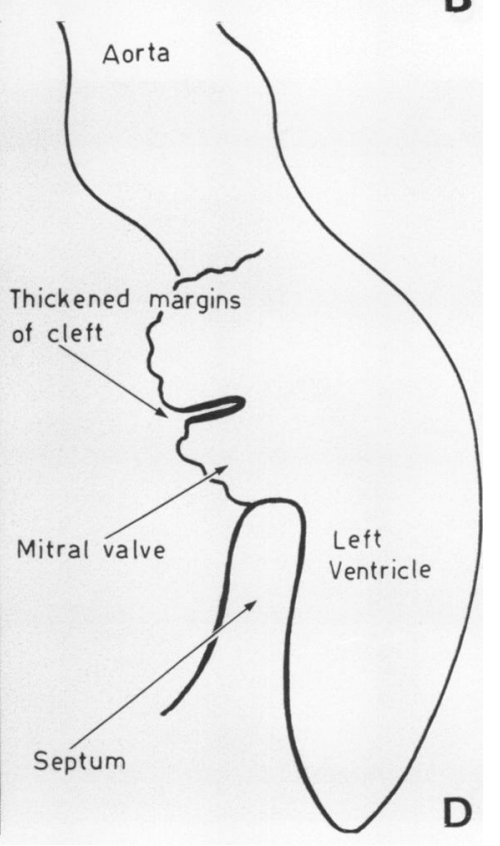

Fig. 4 Systolic appearances of mitral valve. $(A)$ Lateral projection, ostium primum atrial septal defect (operative diagnosis). The mitral valve balloons anterior to the left ventricular cavity. This patient also had a cor triatriatum (not seen on this frame). (C) Left anterior oblique projection with craniocaudal tilt. Ostium primum atrial septal defect (operative diagnosis). It can clearly be seen that the mitral valve is firmly attached to the crest of the septum. It balloons toward the right atrium. 
Fig. 5 Ostium primum atrial shunt because of right ventricular and tricuspid valve hypoplasia (operative diagnosis). Frontal projections of right $(A)$ and left $(B)$ ventricular angiocardiograms. Note the leftward displacement of both free wall annuli, giving an unusually large mitral annulus. Note also the sharp angulation between anterior mitral leaflet and the free wall attachment of the mitral valve, as in Fig. $2 A$.

Fig. 6 Common atrioventricular orifice $(P=1 \cdot 00)$. This patient also had inversus-concordantdouble outlet right ventricle with pulmonary stenosis and dextrocardia. This lateral left ventricular angiocardiogram in diastole shows a rhomboidal common atrioventricular orifice straddling the ventricular septum. Both great arteries originate from the right ventricle.
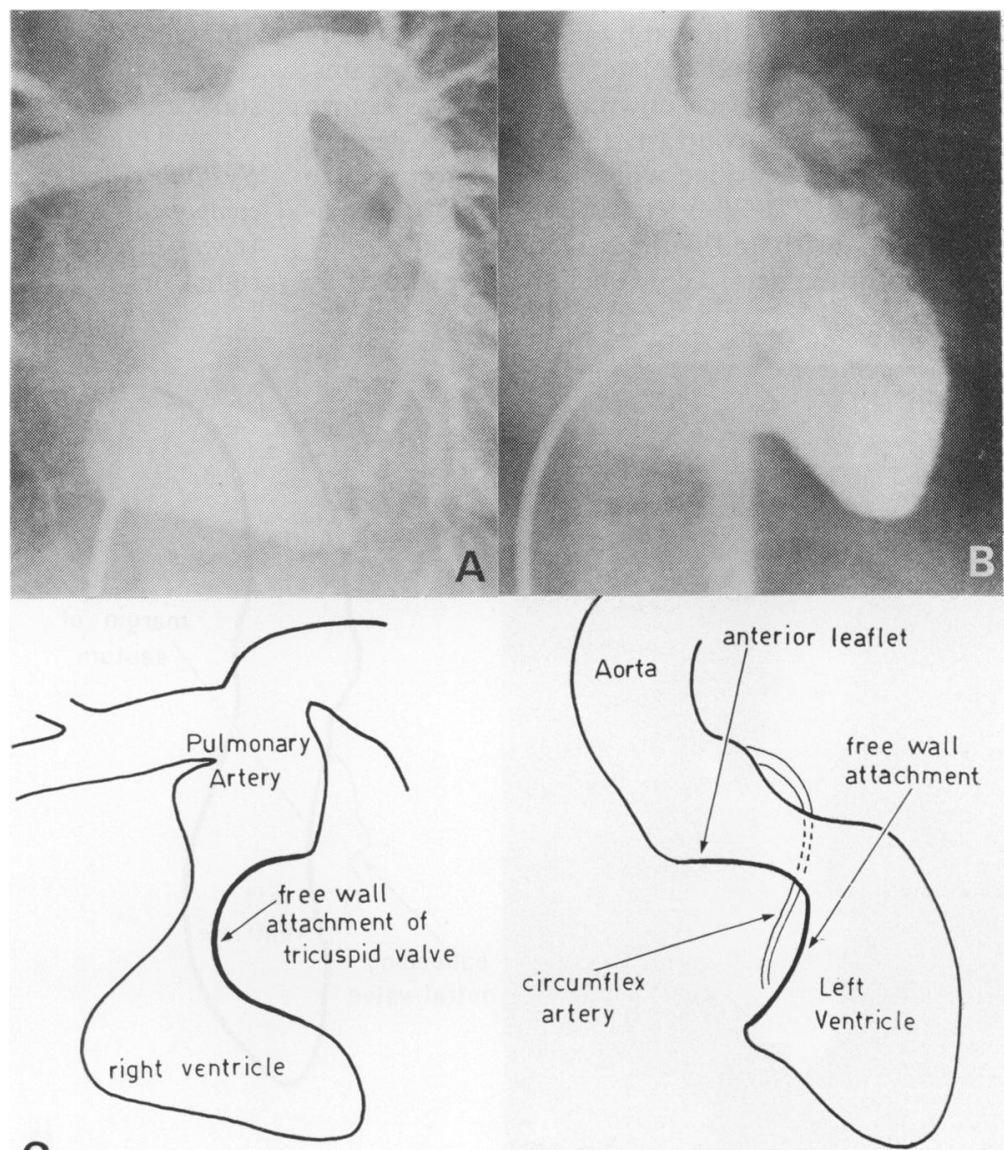

D
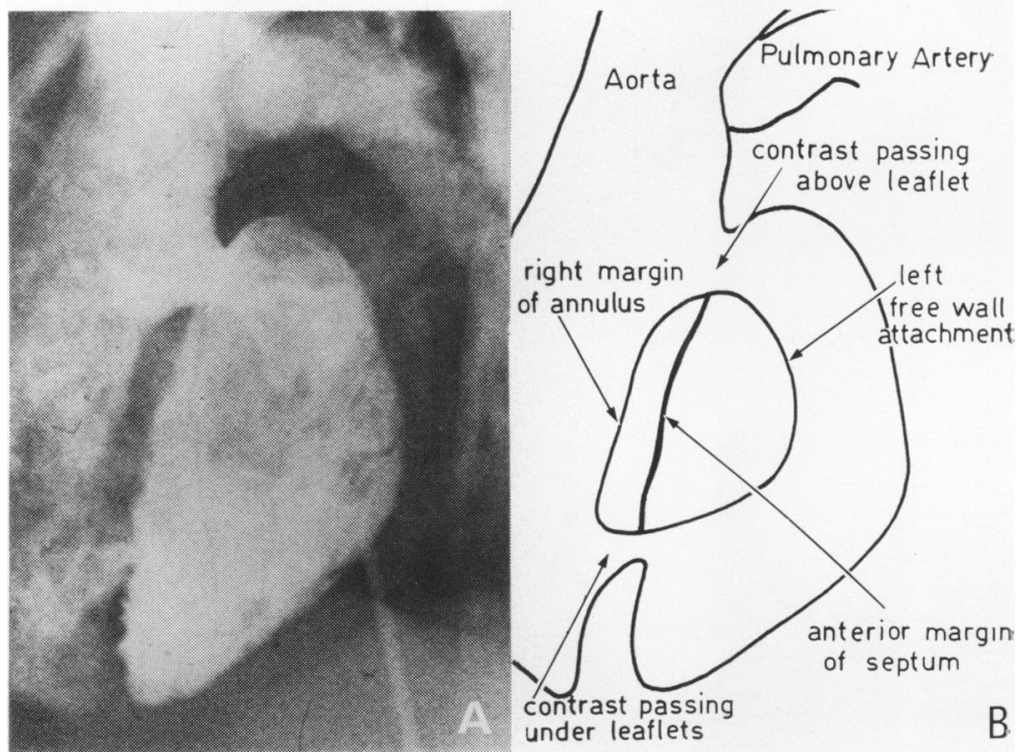
Table 3 Significance of direct angiocardiographic demonstration of common $A V$ orifice in 60 patients with independently confirmed diagnosis

\begin{tabular}{lccc}
\hline & \multicolumn{2}{l}{ Common AV orifice visualised } \\
& No & Yes & Total \\
\hline $\begin{array}{l}\text { Ostium primum } \\
\text { Common AV orifice- }\end{array}$ & $29(100 \%)$ & 0 & 29 \\
$\begin{array}{c}\text { 'attached' anterior leaflet } \\
\text { Common AV orifice- }\end{array}$ & $9(50 \%)$ & $9(50 \%)$ & 18 \\
'free' anterior leaflet & $2(14 \cdot 4 \%)$ & $11(84 \cdot 6 \%)$ & 13 \\
Total & 40 & 20 & 60 \\
\hline$\quad \chi=32 \cdot 1$ & & \multicolumn{2}{c}{$P<0 \cdot 0001$}
\end{tabular}

projections, to identify contrast medium crossing above the anterior bridging leaflet or leaflets or below the posterior bridging leaflet during systole (Fig. 7). One disadvantage of craniocaudal tilt was that it became extremely difficult to recognise contrast medium passing above the anterior leaflet, because this critical region overlapped the usually opacified atria and origin of the great arteries. In other cases a broad band of contrast medium clearly crossed from one ventricle to the other throughout the width of the atrioventricular orifice (Fig. 3A). These signs were never seen in ostium primum, but occurred in

Table 4 Site of selective ventricular angiocardiogram compared with visualisation of common $A V$ orifice

\begin{tabular}{|c|c|c|c|}
\hline . & $\begin{array}{l}\text { Common } A V \text { orifice on } \\
L V \text { angio }\end{array}$ & $\begin{array}{l}L V \text { angio done; no common } \\
A V \text { orifice }\end{array}$ & No $L V$ angio \\
\hline $\begin{array}{l}\text { Common AV orifice on } \mathrm{RV} \text { angio } \\
\mathrm{RV} \text { angio done; no common } \mathrm{AV} \text { orifice seen } \\
\mathrm{RV} \text { angio not done }\end{array}$ & $\begin{array}{l}8 \\
4 \\
8\end{array}$ & $\frac{8}{-}$ & - \\
\hline
\end{tabular}

Table 5 Projections in which common AV orifice identified on LV angiocardiograms

\begin{tabular}{|c|c|c|c|}
\hline $\begin{array}{l}\text { Angio finding } \\
\text { Independent diagnosis } \\
\text { Projection }\end{array}$ & $\begin{array}{l}\text { Common } A V \text { orifice seen } \\
\text { Common } A V \text { orifice }\end{array}$ & Not known & $\begin{array}{l}\text { Common } A V \text { orifice not seen } \\
\text { Common } A V \text { orifice }\end{array}$ \\
\hline Lateral & $3+$ & $\mathbf{0}$ & \} 1 \\
\hline Left anterior oblique without craniocaudal tilt & 7 & 1 & 1 \\
\hline Left anterior oblique with craniocaudal tilt & 2 & 1 & 1 \\
\hline
\end{tabular}

*two also seen in lateral but not included there.

ttwo also seen in other projections (one frontal and left anterior oblique, one left anterior oblique only) but not included in left anterior oblique.

Table 6 Systolic traverse of atrioventricular orifice above anterior leaflet, below posterior leaflet, or across whole width

\begin{tabular}{|c|c|c|c|}
\hline & $N o$ & Yes & \\
\hline $\begin{array}{l}\text { Ostium primum } \\
\text { Common AV orifice-'attached' anterior bridging leaflet } \\
\text { Common AV orifice-'free' anterior bridging leaflet }\end{array}$ & $\begin{array}{r}29(100 \%) \\
7(38.9 \%) \\
3(23.1 \%) \\
39\end{array}$ & $\begin{array}{l}0 \\
11(61 \cdot 1 \%) \\
10(76 \cdot 9 \%) \\
21\end{array}$ & $\begin{array}{l}29 \\
18 \\
13 \\
60\end{array}$ \\
\hline
\end{tabular}

$$
x^{2}=31.05
$$

$\mathrm{P}<0.0001$

Table 7 Right ventricular outflow tract opacification from left ventricle on first systole

\begin{tabular}{|c|c|c|c|c|}
\hline & $\begin{array}{l}L V \text { outflow } \\
\text { No }\end{array}$ & $\begin{array}{l}\text { fication } \\
\text { Yes }\end{array}$ & Uncertain & \\
\hline $\begin{array}{l}\text { Ostium primum } \\
\text { Common AV orifice-'attached' anterior bridging leaflet } \\
\text { Common AV orifice-_free' anterior bridging leaflet }\end{array}$ & $\begin{array}{c}16(55 \cdot 2 \%) \\
1(5 \cdot 6 \%) \\
0(0 \%) \\
17\end{array}$ & $\begin{array}{l}3(10 \cdot 3 \%) \\
12(66 \cdot 7 \%) \\
11(84 \cdot 6 \%) \\
26\end{array}$ & $\begin{array}{r}10(34.5 \%) \\
5(27 \cdot 8 \%) \\
2(15 \cdot 4 \%) \\
17\end{array}$ & $\begin{array}{l}29 \\
18 \\
13 \\
60\end{array}$ \\
\hline
\end{tabular}

$X^{2}=30.2 \quad P<0.0001$


67.7 per cent of cases with common orifice, there being no significant correlation within the latter group with the type of attachment of the common leaflets (Table 6). In certain instances the presence of systolic traverse was most easily confirmed with the onset of the next diastole, since contrast medium was then seen trapped behind the leaflet.

Chamber opacified with first ventricular systole As expected, it was more likely for immediate filling of the right ventricular outflow tract from a left ventricular angiocardiogram to occur with common orifice than with ostium primum, but in many cases, particularly where only frontal and lateral planes had been exposed, it was extremely difficult, even on cine angiocardiograms, to distinguish right atrium from ventricle. In three cases of ostium primum, immediate right ventricular outflow tract filling was confidently (but presumably erroneously) diagnosed (Table 7).

Table 8 Relation between diagnosis and $R V$ systolic pressure

\begin{tabular}{lccccc}
\hline & \multicolumn{2}{c}{$R V$ systolic pressure (mmHg) } & & \\
& $<40$ & $40-60$ & $60-80$ & $80-100$ & $>100$ \\
\hline Ostium primum & $13(44 \cdot 8 \%)$ & $8(27 \cdot 6 \%)$ & $8(27 \cdot 6 \%)$ & 0 & 0 \\
Common AV orifice-'attached' anterior bridging leaflet & $1(5 \cdot 6 \%)$ & $3(16 \cdot 7 \%)$ & $5(27 \cdot 8 \%)$ & $8(44 \cdot 4 \%)$ & $1(5 \cdot 6 \%)$ \\
Common AV orifice-'free' anterior bridging leaflet & $1(7 \cdot 7 \%)$ & $2(15 \cdot 4 \%)$ & $4(30 \cdot 8 \%)$ & $6(46 \cdot 2 \%)$ & 0 \\
& 15 & 13 & 17 & 13 \\
& & & 14 & 1 \\
\hline
\end{tabular}

Fig. 7 Systolic traverse above and below bridging leaflets. In both angiocardiograms the films actually shown are in early diastole so as to show the valve annulus, but contrast medium passed to the position shown in the preceding systole.

(A) Lateral projection, right ventricular angiocardiogram. Contrast medium is crossing above the anterior bridging leaflet. The patient had a rightto-left shunt caused by severe pulmonary vascular obstructive disease. At necropsy, neither bridging leaflet was attached to the ventricular septum, and the anterior bridging leaflet was supported on the right side by a conjoined anterolateral papillary muscle only.

(C) Left ventricular

angiocardiogram, left anterior oblique position with craniocaudal tilt. Contrast medium has passed beneath the posterior bridging leaflet. At operation both bridging leaflets were attached by short chordae tendineae to the crest of the ventricular septum.
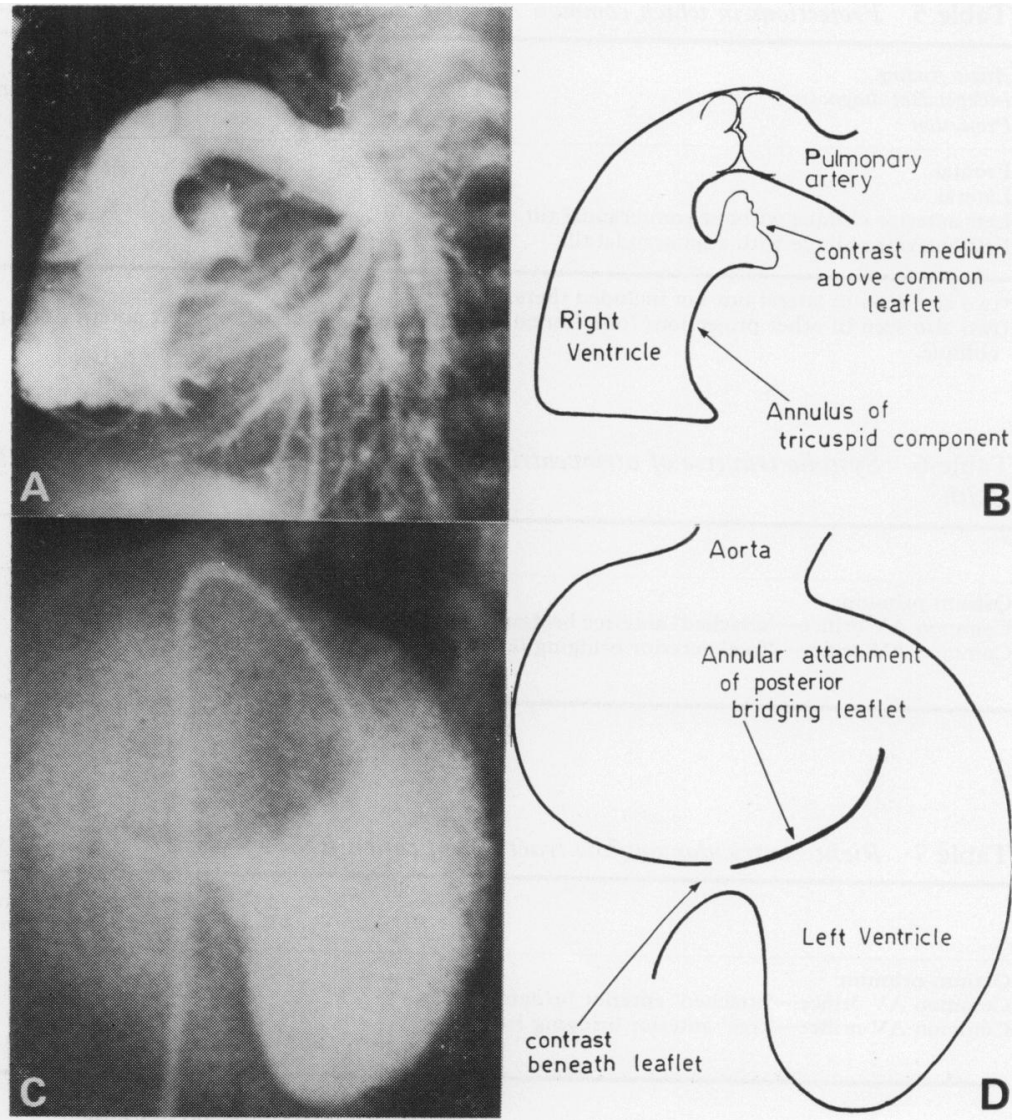


\section{Relation with ventricular systolic pressures}

It was possible to establish a significant correlation between anatomical diagnosis and either right ventricular systolic pressure alone or its ratio with left ventricular pressure. However, despite the wide age range of patients (from 1 day to14 years) the correlation was no better for pressure ratio than for absolute right ventricular peak systolic pressure. Thus, for brevity, the latter only is presented (Table 8). The right ventricular systolic pressure was below $80 \mathrm{mmHg}$ in all cases of ostium primum, and $60 \mathrm{mmHg}$ or above in $24(77.4 \%)$ cases of common orifice.
Table 9 Value code for variables in discriminant function

RV systolic pressure ( $\mathrm{mmHg}$ ) (RVR)

$1=<402=40=593=60-794=80-995=>100$

Common AV orifice (CAVO) visualised angiocardiographically (CAVO) $0=$ no $1=$ yes.

Systolic jet above or below anterior or posterior leaflets, or across width of AV orifice (SYSJET) $0=$ no $1=$ yes.

Immediate RV outflow tract filling from LV injection (RVOT) $0=$ no $1=$ uncertain $2=$ yes

Anterior attachment mitral valve seen (ANTACH) $0=$ no $1=$ yes Systolic jet above anterior leaflets or left anterior bridging leaflet (ABL) $0=$ no $1=$ yes'

Systolic jet across width of AV orifice (ACROSS) $0=$ no $1=$ yes. Systolic jet beneath posterior bridging leaflet $(P B L) 0=$ no $1=$ yes

Table 10 Discriminant function analysis

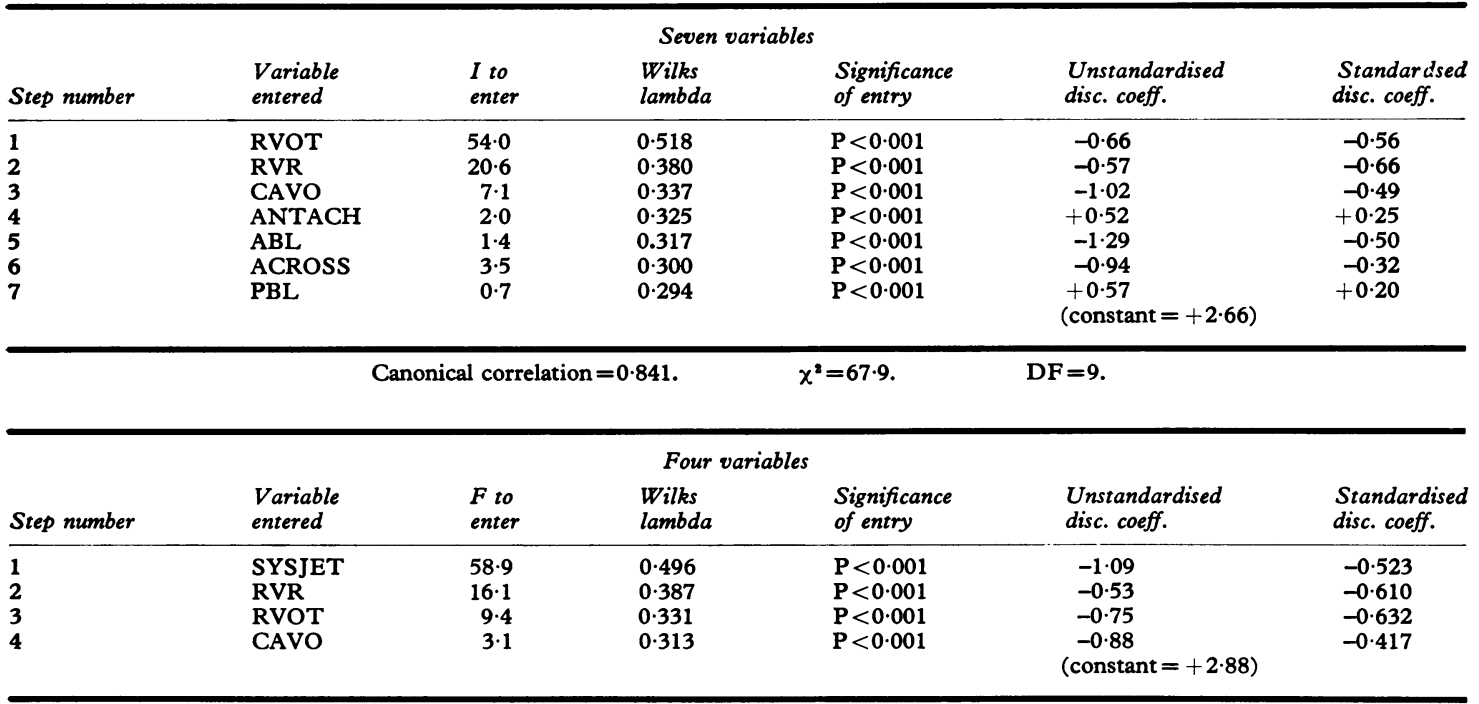

Canonical correlation $=0.829$.

$\chi^{2}=66 \cdot 1$.

$\mathrm{DF}=4$.

Abbreviations of variables as in Table 9. DF, degrees of freedom; disc. coeff., discriminant coefficient.
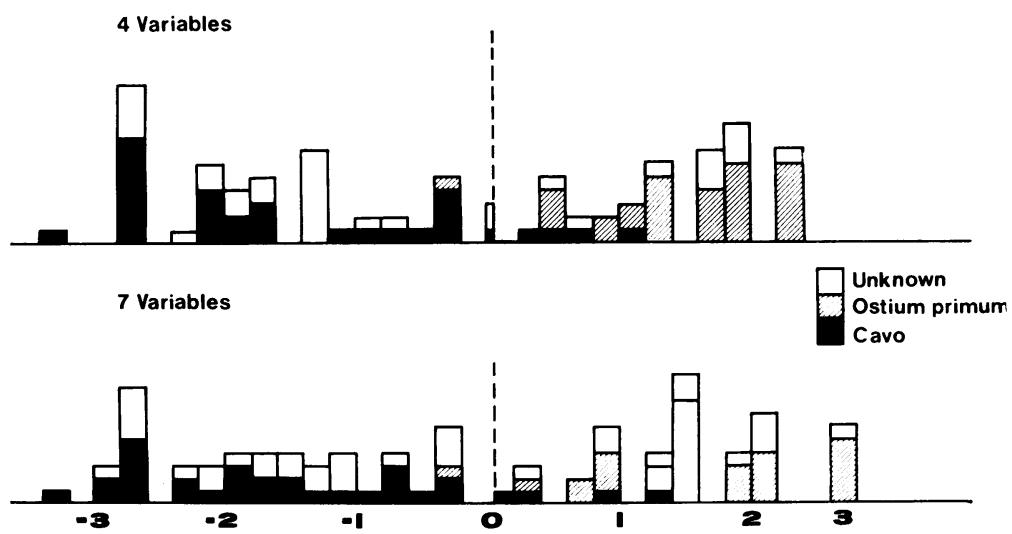

Fig. 8 Histogram of the discriminant scores for each patient, using the four or seven variables listed in Table 10. The dotted line represents the computer derived line of distinction between the diagnosis, with common atrioventricular orifice to the left and ostium primum atrial septal defect to the right. Discrimination with seven variables produces slightly better separation, with one less misclassification. 
DISCRIMINANT FUNCTION ANALYSIS

This was originally carried out with inclusion of all the variables detailed, together with actual rather than coded right ventricular systolic pressure ratio. Though in fact all variables considered were at one stage admitted by the stepwise discrimination at a statistically significant level, discrimination on seven variables separated the two groups common orifice and ostium primum best, as judged by the criteria of minimising Wilks' lambda and maximising canonical correlation. This discriminant function has been used to calculate probabilities of diagnosis for the patients without independent confirmation of diagnosis illustrated in the paper. However, from the practical point of view, discrimination on four variables alone is almost as effective. Fig. 8 and Table 10 compare these discriminants, and Table 9 gives the coding of the variables concerned. Both discriminants incorrectly diagnosed ostium primum in the presence of common orifice in four patients. In each of these four the anterior and posterior leaflets were attached to the crest of the ventricular septum; three only had frontal and lateral left ventricular angiocardiograms. In one patient with an ostium primum, common orifice was incorrectly diagnosed presumably because of an associated large trabecular septal defect. A correct diagnosis was achieved in 91.7 per cent of known cases. The standardised discriminant function coefficients (Table 10) are weighted in such a way as to eliminate the effect of differences in span of the variables concerned, and therefore give a good picture of the relative importance of each factor as a discriminant. It is clear that the most important are the right ventricular systolic pressure and immediate right ventricular outflow tract filling. The diastolic appearance of common orifice and anterior attachment of the mitral valve, and a systolic jet across the atrioventricular orifice are less important since, when present, they are informative, but when absent, less so.

In short, when the sum:$2.88-(1.09 \times$ value for SYSJET $)-(0.53 \times$ value for RVR $)-(0.75 \times$ value for $R V O T)-(0.88 \times$ value for CAVO)

exceeds 0.05 , the values being as coded in Table 9, the likely diagnosis is ostium primum. When that sum is negative, or positive and less than 0.05 , the likely diagnosis is complete atrioventricular canal.

At no stage was a significant second discriminant function obtained which would divide common orifice into different diagnostic categories in addition to separating it from ostium primum.

\section{Discussion}

Previous angiocardiographic descriptions of atrio- ventricular defects have concentrated almost exclusively on the abnormal septal 'attachment' of the mitral valve (Baron et al., 1964; Girod et al., 1965; Rastelli et al., 1967; Gotsman et al., 1968; Somerville and Jefferson, 1968; Tenckhoff and Stamm, 1973; Blieden et al., 1974; Rastelli et al., 1976). The free wall attachment as seen in the frontal plane has either been ignored or dismissed as normal (Baron et al., 1964; Somerville and Jefferson, 1968). Rastelli and colleagues (1967) correctly identified the line of attachment of the mural (left lateral) leaflet in a patient with a 'free-floating anterior common leaflet' and further recognised the importance of the fact that the 'anterior common leaflet' was not attached to the septum, but concluded that the resulting appearance was characteristic of this particular variety of complete defect. Other forms of complete defect with indirect attachment of anterior leaflet tissue to the septal crest were held to show the same angiocardiographic abnormality as was present in ostium primum.

In considering the radiographic appearances of other forms of congenital mitral anomalies (Macartney et al., 1976), we had taken as fundamental the principle that sharp interfaces between opacified and non-opacified blood appearing with each diastole and disappearing with each systole could only be the result of valve leaflets and the annuli to which they attached (rarely, an aneurysm of the interventricular septum may behave in the same way). The common orifice of a complete atrioventricular defect is surrounded by a common annulus, the free wall attachment. A septal annulus only exists in so far as leaflet tissue is attached directly to the septum, and is therefore present in ostium primum but absent or else grossly deficient in complete defects. If, therefore, the appearances of complete defects are interpreted as the result of an abnormally positioned septal attachment, either the theory, the interpretation, or both, must be incorrect. The evidence here presented strongly supports the theory, but may also explain why problems with interpretation, self-evidently present, have occurred.

Observation of the diastolic cleft, which marks the septal mitral attachment in ostium primum, and the circumflex left coronary artery, which marks the free wall attachment, has enabled these two to be distinguished, and has led to two further points of distinction. The septal attachment is puckered, because it is abnormal, and associated with numerous very short chordae running from the crest of the septum to the medial aspect of the anterior and posterior leaflets. The free wall attachment is smooth, as it normally is.

Having established these fundamentals, it is then possible to compare the position of the annulus in 
atrioventricular defects with that in patients with normal mitral valves. The region of mitral/aortic continuity provides a reference point, though it is not in fact fixed, because in atrioventricular defects the aortic valve has not reached its normal position wedged between the mitral and tricuspid valve. It is too anterior and too far to the right relative to both valves (Piccoli et al., 1979a). In atrioventricular defects (Fig. 9) the entire mitral annulus or the mitral component of the common orifice is abnormally positioned relative to the area of mitral/ aortic continuity so that instead of 'looking' downwards, leftwards, and anteriorly, it 'looks' more or less directly leftwards. The region of the mitral annulus that is most abnormal is the septal attachment, but the whole annulus is displaced relative to the aortic valve. The apical displacement of the septal attachment corresponds to the deficiency of the interventricular septum noted in anatomical studies (Blieden et al., 1974; Ebert and Goor, 1978) and is associated with reorientation of the tricuspid annulus or component. This is because apical displacement of the septal attachment of the tricuspid valve towards the apex rotates the tricuspid annulus clockwise as seen from above. Thus the plane of the annulus 'looks' more anteriorly, and the lateral free wall attachment may even move to the left.

The only difference from these appearances in the case of complete malformations is that the direct septal attachment disappears largely or completely, leaving a common annulus (Fig. 9).

Because the realigned mitral annulus 'looks' more or less directly leftward, the septal attachment and free wall attachment in ostium primum lie essentially one in front of the other. Thus either can produce the characteristic 'scooped-out' appearance of the right margin of the left ventricular cavity in the frontal plane (Fig. 1). As Table 2 indicates, in only just under half the patients with ostium primum could this appearance be attributed to the septal attachment. In the remainder, as in the patients with complete defects, the abnormal 'scooped-out' appearance of this region was the result of the free wall attachment. The anatomical appearance of the 'scooped-out' septal crest which characterises atrioventricular defects is extremely beguiling because it looks so like the angiocardiographic abnormality. This resemblance can be enhanced by photographing the specimen in a mirror, reversing the negative (Blieden et al., 1974) or painting the septal crest with contrast medium (Tenckhoff and Stamm, 1973), but none of these techniques proves that the septal crest can be visualised angiocardiographically in complete atrioventricular defects. It has been suggested that, during diastole, the leaflets float forward to contact the septal crest, thereby trapping contrast medium between it and the leaflets, but this argument ignores the fact that during the preceding systole, contrast medium will have passed to both sides of the septum thus preventing the sharp contrast between nonopacified and opacified blood which is required to
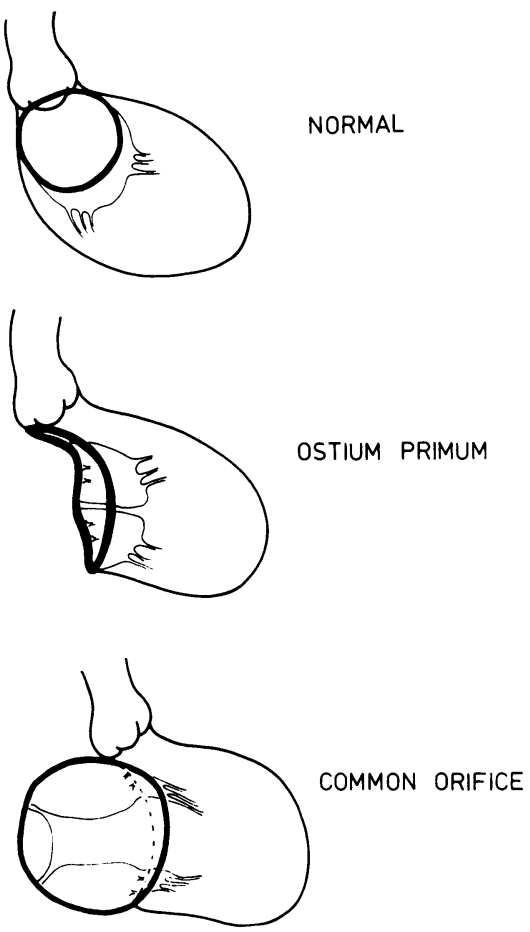

Fig. 9 Diagram to demonstrate the anatomical cause of the radiographic appearances of the mitral valve or component in the frontal view of the left ventricular angiocardiogram in the normal and in partial and complete atrioventricular defects. In each diagram the entire annulus of the mitral valve or common valve is drawn in heavy black. The anterior mitral leaflet is also shown, but for clarity the posterior (mural) leaflet is not. In common atrioventricular orifice both anterior and posterior bridging leaflets are shown.

Partial and complete defects have in common an abnormal position of the free wall attachment of the mitral annulus. They differ in that there is a direct septal attachment in ostium primum atrial septal defect which forms part of the annulus. In common atrioventricular orifice, the septal attachment is missing or deficient. There is therefore no reason why the crest of the septum (dotted) should be visualised

angiocardiographically except in so far as the chordal attachments to the septum are so tightly packed as to prevent passage of contrast medium through the interchordal spaces. Thus the mitral component of the free wall annulus, instead of passing onto the septum, is continuous with the tricuspid annulus component. 
demonstrate this apposition. The septal crest can, of course, be profiled, but then appears as a more or less permanent filling defect, disappearing only if it rotates out of profile. It is our contention that it is only possible to visualise the septal attachment during diastole when contrast medium is not free to cross from one side of the septum to the other during systole. This is the situation in ostium primum, and could only occur in complete defects if the leaflets were attached by short, densely packed chordae tendineae to the septal crest, in other words when there was virtually no ventricular component of the defect. A 'septal attachment' was visualised in two patients in whom the left and right anterior leaflets in a complete defect were attached to the septum but, as has been explained, these were seen on film changer exposures, not on cine angiograms, and were probably the result of passage of non-opacified blood through interchordal spaces.

By filming in oblique projections, the possibility of confusing the septal and free wall attachments of the mitral valve is eliminated, since they no longer overlap. This is one reason why Brandt's expositions of the radiographic appearances (Brandt et al., 1972; Brandt, 1973) are models of clarity. Our own results endorse entirely Brandt's advocacy of the left anterior oblique projection for all varieties of antrioventricular defects, and further provide the clue to its superiority, which is that a common orifice is much more likely to be identified in diastole in the oblique projection than in the frontal and lateral projections. In contrast with Brandt, we have found the right anterior oblique projection helpful only in that it separates atria from ventricles, and therefore allows more certain identification of immediate right ventricular outflow tract (as opposed to right atrial) opacification after injection into the left ventricle. Adding craniocaudal tilt to the left anterior obliquity is of benefit in that it prevents foreshortening of an already deficient trabecular septum, thereby increasing the possibility of detecting additional ventricular septal defects. Indeed in some cases the combination of foreshortening and trabecular septal deficiency was so extreme that the diagnosis of univentricular heart was entertained until craniocaudal tilt was employed. On the other hand, in our experience, adding craniocaudal tilt to a left anterior oblique projection impairs visualisation of the atrioventricular valves, since they become foreshortened.

As predicted from the fundamental anatomy, right ventricular angiocardiography has proved to show abnormalities of the tricuspid valve or component in a number of patients. Where a common atrioventricular orifice was shown, the appearances were diagnostic and left ventricular angiocardiography served only to confirm what was already obvious. When the diagnosis of some type of atrioventricular defect was known from left ventricular angiocardiography, injection into the right ventricle frequently established the diagnosis of a common orifice by demonstrating passage of contrast medium above the anterior leaflet(s), or below the posterior bridging leaflet (Fig. 7A). It is therefore a valuable adjunct to left ventricular angiocardiography in cases where doubt may exist. Furthermore, it is useful in assessing the need for left ventriculography in apparently straightforward tetralogy of Fallot or double right ventricle. The right ventricular angiocardiograms may be diagnostic of the complete defect. Unless they clearly show separate tricuspid and mitral valves, one in each ventricle, left ventriculography should be carried out to exclude the presence of a common orifice, which greatly increases the operative risk (Sridaromont et al., 1975). Left ventriculography is in any case useful for the purpose of excluding additional ventricular septal defects.

The results presented indicate that there is no universally applicable touchstone of either common orifice or ostium primum septal defect. A number of variables need to be considered, which is why discriminant function analysis has been applied. The results are instructive in so far as they indicate the relevance of each variable concerned. In particular, the right ventricular systolic pressure proved to be of considerable predictive value in addition to the angiocardiographic appearances. While it is true that some patients with ostium primum had a high right ventricular systolic pressure (Brandt et al., 1972) and some with a common orifice had low right ventricular pressure, this predictor is widely applicable and no less accurate than, say, immediate filling of the right ventricular outflow tract from the left ventricle. For those disinclined to apply mathematical formulae to diagnosis, the results of the discriminant function equation may be roughly expressed as follows:

Whatever the right ventricular pressure, the diagnosis of common orifice is established if two of the following angiocardiographic signs are present, (a) evidence of a common orifice (b) systolic passage of contrast medium above the anterior leaflet(s), below the posterior leaflet, or across most of the atrioventricular annulus, (c) definite filling of the right ventricular outflow tract on the first systole after injection into the left ventricle. If the right ventricular pressure is 60 to $80 \mathrm{mmHg}$ the diagnosis of a common orifice is established by (c) alone, or by two of (a), (b), or (probable c).

If the right ventricular pressure is $80 \mathrm{mmHg}$ or above any one of the above angiocardiographic 
criteria establishes the diagnosis of a complete defect. If the criteria do not hold good, then the presumptive diagnosis is ostium primum atrial septal defect. Despite the large series of patients studied in whom there was independent confirmation of the diagnosis, no way was found of distinguishing the different varieties of leaflet attachment in complete defects. In particular, the appearance (Rastelli et al., 1967) suggested as being typical of the 'free-floating' anterior leaflet, in which the anterior leaflet makes a sharp angle with the posterior line of attachment of the mitral valve, was frequently seen in all varieties of atrioventricular defects including ostium primum atrial septal defects (Fig. 2A).

The distinction between common orifice and ostium primum on the basis of the presence or absence of leaflet continuity over the crest of the septum has the great merit of leading to an unequivocal classification. However, it should be noted that this is not what is shown angiocardiographically. By angiocardiography one can hope to detect whether or not there is firm fusion of the leaflets to the crest of the septum. The method works because there is rarely continuity between anterior and posterior leaflets unless they are fused to the crest of the ventricular septum.

It is therefore to be expected that transitional forms of the defect, in which there is leaflet continuity but also a ventricular component, would be diagnosed as common atrioventricular orifice on angiocardiography.

We thank Dr Siew Yen Ho for the line drawings.

\section{References}

Bargeron, L. M., Elliott, L. P., Soto, B., Bream, P. R., and Curry, G. C. (1977). Axial cineangiography in congenital heart disease. Section I. Concept, technical and anatomic considerations. Circulation, 56, 10751083.

Baron, M. G., Wolf, B. S., Steinfeld, L., and Van Mierop, L. H. S. (1964). Endocardial cushion defects. Specific diagnosis by angiocardiography. American fournal of Cardiology, 13, 162-175.

Bharati, S., and Lev, M. (1973). The spectrum of common atrioventricular orifice (canal). American Heart fournal, 86, 553-561.

Blieden, L. C., Randall, P. A., Castaneda, A. R., Lucas, R. V., and Edwards, J. E. (1974). The 'goose neck' of the endocardial cushion defect: anatomic basis. Chest, 65, 13-17.

Brandt, P. W. T. (1973). Heart Disease in Infancy. Diagnosis and Surgical Management, p. 103, ed B. G. Barratt-Boyes, J. M. Neutze, and E. A. Harris. Churchill Livingstone, Edinburgh.
Brandt, P. W. T., Clarkson, P. M., Neutze, J. M., and Barratt-Boyes, B. G. (1972). Left ventricular cineangiocardiography in endocardial cushion defect. (Persistent common atrioventricular canal.) Australasian Radiology, 16, 367-376.

Ebert, P. A., and Goor, D. A. (1978). Complete atrioventricular canal malformation: further clarification of the anatomy of the common leaflet and its relationship to the VSD in surgical correction. Annals of Thoracic Surgery, 25, 134-143.

Elliott, L. P., Bargeron, L. M., Bream, P. R., Soto, B., and Curry, G. C. (1977). Axial cineangiography in congenital heart disease. Section II. Specific lesions. Circulation, 56, 1084-1093.

Girod, D., Raghib, G., Wang, Y., Adams, P., and Amplatz, K. (1965). Angiocardiographic characteristics of persistent common atrioventricular canal. Radiology, 85, 442-447.

Gotsman, M. S., Beck, W., and Schrire, V. (1968). Left ventricular cine-angiocardiography in endocardial cushion defect. British Heart fournal, 30, 182-187.

Liberthson, R. R., Paul, M. H., Muster, A. J., Arcilla, R. A., Eckner, F. A. O., and Lev, M. (1971). Straddling and displaced atrioventricular orifices and valves with primitive ventricles. Circulation, 43, 213-226.

Macartney, F. J., Bain, H. H., Ionescu, M. I., Deverall, P. B., and Scott, O. (1976). Angiocardiographic/ pathologic correlations in congenital mitral valve anomalies. European fournal of Cardiology, 4, 191-211.

Nie, N. H., Hull, C. H., Jenkins, J. G., Steinbrenner, K., and Bent, D. H. (1975). Statistical Package for the Social Sciences. McGraw-Hill, New York.

Piccoli, G. P., Gerlis, L. M., Wilkinson, J. L., Lozsadi, Karolyi, Macartney, F. J., and Anderson, R. H. (1979a). Morphology and classification of atrioventricular defects. British Heart fournal, 42, 621632.

Piccoli, G. P., Wilkinson, J. L., Macartney, F. J., Gerlis, L. M., and Anderson, R. H. (1979b). Morphology and classification of complete atrioventricular defects. British Heart fournal, 42, 633-639.

Rastelli, G. C., Kincaid, O. W., and Ritter, D. G. (1976). Atrioventricular Canal Defects, p. 110, ed R. H. Feldt. W. B. Saunders, Philadelphia, London, and Toronto.

Rastelli, G. C., Kirklin, J. W., and Kincaid, O. W. (1967). Angiocardiography of persistent common atrioventricular canal. Mayo Clinic Proceedings, 42, 200-209.

Rastelli, G. C., Kirklin, J. W., and Titus, J. L. (1966). Anatomic observations on complete form of persistent common atrioventricular canal with special reference to atrioventricular valves. Mayo Clinic Proceedings, 41, 296-308.

Rees, P. G., Daly, K., Taylor, J. F. N., Chrispin, A. J., and Macartney, F. J. (1978). Cranio-caudal tilt in angiocardiographic visualisation of congenital heart defects (abstract). British Heart fournal, 40, 1065. 
Somerville, J., and Jefferson, K. (1968). Left ventricular angiocardiography in atrioventricular defects. British Heart fournal, 30, 446-457.

Sridaromont, S., Feldt, R. H., Ritter, D. G., Davis, G. D., McGoon, D. C., and Edwards, J. E. (1975). Double-outlet right ventricle associated with persistent common atrioventricular canal. Circulation, 52, 933-942.

Tenckhoff, L., and Stamm, S. J. (1973). An analysis of 35 cases of the complete form of persistent common atrioventricular canal. Circulation, 48, 416-427.
Wakai, C. S., and Edwards, J. E. (1958). Pathologic study of persistent common atrioventricular canal. American Heart fournal, 56, 779-794.

Requests for reprints to Professor F. J. Macartney, The Hospital for Sick Children, Great Ormond Street, London WC1N 3JH. 